\title{
3. Foreseeable Shocks and the Critical Challenges Facing Humanity in the Twenty-First Century
}

\author{
Pierre-Alain Schieb
}

My contribution to this volume is about the notion of foreseeable shocks and what their consequences or implications are for risk governance. But I have expanded the title to its current form because the chapter is also a discerning conversation about a new class of global risk, the likes of which we have not seen before - at least over the course of the postwar generation.

For the past 18 years, I have belonged to the International Futures Programme (IFP) of the Organisation for Economic Cooperation and Development (OECD), which is a slightly different animal to, say, the community structure of the OECD or the working parties in the OECD. In contrast to these institutions, the IFP has a number of degrees of freedom to select themes and to invite international organisations, NGOs and members of the private sector to collaborate with us. We are also to a large extent a self-funded program, with 95 per cent of our budget coming from voluntary contributions.

Unlike other OECD institutions, however, we don't need all 34 member countries to be aligned about priorities. Consequently, we can have six, seven or 10 countries help decide what should be our next pioneering or pilot project. I insist on this point because if you think about future-proofing the state, the first lesson is that one way or the other governments in member countries have to have some kind of foresight strategy or foresight unit. It could be embedded at the prime ministerial level of cabinet; it could be in different departments or outside the government altogether, as with the case of think tanks in the United States.

Several models are available to try to make sure that the future is to a certain extent taken into account. And yet, the only country we know of having something related to the long-term future embedded into the constitutional bylaws is Finland. Every new Finnish prime minister coming into power has to deliver a speech to Parliament about his or her 15-year vision for Finland, and also serves on a permanent commission of the future in the Parliament.

Finland's institutional arrangements to facilitate long-term planning are exceptional in the world and raise an interesting question: how do we incentivise the political system to give more weight to the long run in a context in which all 
the political incentives typically lead to planning that only extends the length of an electoral cycle? This is particularly difficult - and pressing - in the current global context, where we are faced with short-term economic difficulties.

So what mechanisms, institutional arrangements or processes would I recommend at the political and national governmental levels to encourage longterm thinking? That is a difficult question, because 'one size fits all' will never work. Finland's approach may be exceptional, but there are other approaches to long-term planning around the world. In other cases, the notions of consultation and inquisitiveness - rather than a constitutional requirement as in Finlandalso result in a longer-term approach to planning.

Take Sweden. When they were faced with the long-term problem of what to do with nuclear waste, the institutions in charge of the problem selected three spots on the coast of Sweden. What they then did was supply funding to local communities to ensure they had access to the expertise of independent scientists. This is an example of addressing long-term potential challenges, albeit by a different mechanism.

Probably the first deficiency we have in the government structure of OECD countries is that not all of them have the same quality of research about the policies relating to emerging issues - something we reported on in July 2011 (OECD 2011). In so doing we were trying to establish a set of policy options (everything we do is aimed at delivering policy options for governments). We also know we have to have a positive attitude to shocks, because shocks can be positive - they can be a disruptive technology, change the market structure or have other positive impacts. In this chapter, however, I will explore the kind of damaging shocks that may happen, especially the global ones.

Twelve years ago the IFP launched its first project on emerging risk, and since then we have recognised several trends: growing interdependence in the economic, environmental and social spheres; increased interconnectedness and also complexity of systems; and an increased concentration of assets and population.

Two notes on this: first, even if you do not consider climate change or any change in the occurrence of important share-damaging hazards, the trend is leading to a high concentration of population and assets. This trend is growing even in OECD countries and is creating a lot of potential damage and casualties. So to a certain extent, you could split up the debate and say that even if we take constant probabilities of occurrence into account, there is still greater potential damage from any kind of event like that.

The second note is that, as you may remember in 2007, just when the subprime mortgage crisis was supposed to stop, we had a new economic factor due to 
globalisation, which was that economists were starting to recognise a notion of synchronisation of economies on a global scale. And I am reminded of this with the current debt crisis many countries are facing, because a possible consequence of this high level of debt is that we could again see a kind of synchronisation of microeconomic trends - but this time in the declining trend. This would be very harmful, and is something I will explore later in this chapter, because there is a big difference between what you usually call a large-scale disaster and a global shock.

What constitutes a global shock? First, you need a vector, itself characterised by the notion of mobility - whether it be the mobility of people, the mobility of money, the mobility of information, the mobility of viruses or the mobility of goods. Often a high level of mobility occurs because many of the potentially damaging global shocks are local shocks drifting or cascading into other continents or countries.

Returning to the notion of population concentration, even in OECD member states people are continuing to migrate from the country to the city (currently 78 per cent of OECD members' populations live in cities; within 10 or 15 years that figure will be above 80 per cent). Moreover, migratory trends within these countries cannot be characterised just by urbanisation: within many OECD countries there is also a trend of transmigration to coastal areas - particularly among retirees. Population concentration increases your vulnerability to shocks.

Let me now move on to an example of future-proofing - in this case, concerning aviation safety. Single European Sky ATM Research (SESAR) is the codename for Europe, and NextGen is the codename for the United States. The only thing you have to understand about these new air traffic-control systems is that they are examples of conversion technology. They represent a new level of complexity, whereby assistance is given but a pilot is not needed. (I am a pilot myself and I have learned that now I have become a mission manager, I will just run computers - something that is perhaps not so pleasing for both the passenger and myself.)

Despite my personal reservations with these developments, they are obviously highly beneficial because they are leading to safer travel with fewer collisions; the aim is a shorter separation time when you land or take off at an airport. Although this is a good aim, it also leaves the regulators with a more difficult task, because the systems won't be fully operational for 15 years; until that time there will be two systems in place. So although the new technology will eventually be beneficial, its rollout is potentially causing problems for the regulators. 
Future-Proofing the State

\section{The Future Global Shocks Project}

The process we had for this OECD project was to have a steering group of delegates from 15 governments, with the additional input of five or six multinational companies. In this way we like to always have a blend of academics, research institutes, private sector representatives and governments to make recommendations, and to make our analytical component as robust as possible. To this end the steering group decided to go with five case studies. These five studies are not necessarily of the most important or even most damaging events, but rather represent an important sample of global trends.

To select the case studies we first consulted the World Economic Forum, which every year produces a risk map on a global scale. This provided an easy starting point to select our five case studies. When consulting the risk map, we were particularly interested in cases that illustrated the propagation of local to global shocks and rapid-onset shocks, and also complexity theory agent-based models, which look for tipping points.

Of 25-35 potential threats, we selected the following five case studies: pandemics, financial crises, cyber security, solar storms and social unrest. Of course, pandemics are a good example of special propagation, because they usually start in one place and then become a kind of global shock. When it reaches this stage, we know that part of the response is dealing with quarantine, and closing airports, schools and so on. So it's an example of spatial, geographical propagation.

Solar storms are an interesting case, with a range of possibly damaging consequences. These fall into three categories: spacecraft effects; ionospheric effects (concerning the atmosphere between the stratosphere and the exosphere); and ground effects. Spacecraft effects include things like astronaut radiation, solar cell damage and solar flare radiation; ionospheric effects include enhanced ionospheric currents and disturbances, aircraft crew and passenger radiation and navigation problems; ground effects include geomagnetically induced currents in power systems, signal scintillation, HF radio wave disturbance, pipeline corrosion and disturbed reception. In the worst-case scenario, a solar storm could lead to the collapse of 400000 -volt transformers and with them the entire power system.

NASA and the US National Academy of Sciences have predicted that in such an event it would take four hours for the first effects to assert themselves; within a month there would be a complete collapse of the economy and society. Recovery from such an event could take years. Moreover, we simply do not have a stockpile of quality transformers anywhere, so you cannot simply replace them. There are ways of shielding transformers, but this can be extremely costly. 
There have already been examples in history of this type of disaster occurring. The Carrington Event of 1859 was a geomagnetic storm that produced the largest known solar flare. At the time there were no powerlines, computers or airlines, but there was extensive damage to the telegraph system in Europe and North America. We have seen recent geomagnetic storms cause damage in Sweden, Canada and parts of the United States, but nothing compared with the scale of the Carrington Event. In fact, these recent storms are estimated to be onequarter as powerful as the Carrington Event. Another storm on the scale of the Carrington Event would lead to extensive damage.

The ash cloud over Europe in 2010 caused by the eruption of the Icelandic volcano Eyjafjallajökull was a good example of the danger of having just one disaster-prediction model - in this case, based in the United Kingdom. The principal problem was that neighbouring countries affected by the ash cloud had no access to the model so had no way of observing where the cloud was moving, the size of the ash particles, how they would affect aeroplane engines and so on.

This created a difficult situation for many countries, and is probably why most of Western and Central Europe chose to close their airports. The havoc Eyjafjallajökull wreaked on Europe's air traffic was a good example of what happens when you lack resources on a global or even multilateral scale, especially during the crisis itself.

Still on the subject of aviation safety, the United Kingdom recently published a Chatham House report concerning everything that relies on airfreight transport. The report concluded that if we were to face another volcanic eruption that produced a cloud that stayed for months rather than weeks, there would be all kinds of implications for the economic system.

I will now move to cyber security. Cyber security was the subject of a recent report by our team in the United Kingdom. They reached the same conclusion as our counterparts in the United States and France: there is no case for global shocks on the basis of a cyber security attack, at least in the next 10 years or so.

When this UK report was published in January 2011, we had more than 100 quick reactions all over the world. They were mainly comments made by journalists or experts who believed we had underestimated the risk of cyber attacks, and that they could lead to global shocks. They were confused by the fact you can have a strong attack on Australia or perhaps a strong attack targeting a particular company without it being classed as a global shock. But even though these events can be devastating for the victims, it is not a global shock if it doesn't have worldwide economic ramifications. After we received these criticisms, we put more in our report about what the difference is between a large-scale disaster and a long-term global shock. 


\section{Global Shocks: Lessons to learn}

This brings us to the first of my concluding points: a global shock is quite different from a large-scale disaster. The second lesson we need to learn is that while we think there are increased opportunities for global shocks to occur in the twenty-first century, society at large is now quite resilient. Even if the preconditions for a global crisis as I have stated earlier in this chapter are met, there is now a high premium on international cooperation.

But we cannot take this for granted. First, there needs to be a greater level of international cooperation in terms of scientific mechanisms to meet potential threats. This also means more monitoring of potential threats. Second, to effectively combat potential threats there needs to be a continuation of projects; it doesn't work to discontinue projects every few years. Instead, governments need to be consistent over time- and climate change is a pertinent reminder of this.

Third, diversity is crucial: you don't want to put all your eggs in one basket. Because if, for example, you have software that is in 85 per cent of global computers, we think that's a big risk. In such situations the system should be dismantled so as to avoid a global engineering failure. We don't want that kind of monopoly.

Another recommendation is the stockpiling of supplies in case of a crisis - be it of food or whatever. Undoubtedly this would be very costly, but it probably could be done on a regional basis. The success of such a scheme would depend on having a very accurate real-time system to know where those resources are and what is in them.

But building reserves and building redundancy, of course, run contrary to all the trends in the public and private sectors over the past 30 years. In a time of economic constraint, convincing people to do this can be difficult.

So it's a combination of having real physical reserves and tracking where those reserves are and what is in them. But who will pay for them? During a global shock you cannot rely on your nice neighbour to provide potable water, generators and spare parts; perhaps the private sector could help foot the bill. This goes even further for vaccines and rare resources; we know that when it comes to pandemics, the countries that are home to the larger drug companies feel they are quite safe.

If you don't have a drug company in your own country, however, you start to question who will have priority for the delivery of vaccines. These are the things countries and regions must start thinking about, because when a crisis strikes, you can't rely on others to help you sustain your population's needs. 
Getting back to the issue of global science mechanisms, one of the big questions is: who will monitor them? It should be done affordably, so international cooperation is critical - because if you share the cost you have no redundancy; no country is in the mood to do it themselves.

We need, then, to inject more science during crises to better understand what is happening and to invest in real-time models to evaluate the location of resources or evacuation plans and other aspects of preparedness. So you have a range of questions about this, and, as I said, if you have more diversity you need less redundancy, and you are not competing for the same resources as your neighbours.

The same goes for the private sector. In the private sector the key factor will be sharing data; the sector needs to get over its current preoccupation with confidentiality and trade secrets. One way we can start to make this happen is to ask the private sector to release some of the duties regarding deregulation, and to provide greater access to their transactions: perhaps transactions of their system or environmental transactions. It could be a trade-off: we give the private sector more freedom in certain areas if they give us more access to their data.

\section{Reference}

Organisation for Economic Cooperation and Development (OECD). 2011. Future Global Shocks: Improving Risk Governance (Paris: OECD). Available from: <http://www.oecd.org/governance/48329024.pdf>. 
This text taken from Future-Proofing the State: Managing Risks, Responding to Crises and Building Resilience, edited by Jonathan Boston, John Wanna, Vic Lipski and Justin Pritchard, published May 2014 by ANU Press, The Australian National University, Canberra, Australia. 